\title{
Г.А. Фомин
}

\section{ЕВРОПЕЙСКИЕ ХУДОЖЕСТВЕННЫЕ ТРАДИЦИИ И РУССКАЯ АКАДЕМИЧЕСКАЯ ШКОЛА РУБЕЖА ХІХ-ХХ ВВ. ПРОБЛЕМА КУЛЬТУРНОЙ ИДЕНТИЧНОСТИ}

\begin{abstract}
Статья посвящена проблеме преемственности традиций в Петербургской академии (Высшем художественном училище) рубежа XIX-XX вв. Формирование системь мастерских в Академии художеств рассматривается как углубление отечественной художественной школь в европейскую академическую традицию, заимствованную в XVIII в. в виде системы классов, модели, которая к кониу ХІХ в. начала исчерпьвать себя и морально устаревать. Этот факт и неудачи «передвижнической» реформы 1893-1894 г2. проявили в русской академической школе проблему культурной идентичности, вынудившую молодое поколение студентов-художников отправиться для завершения образования в зарубежные заведения. Более всего ими были предпочитаемы частные студии Парижа и Мюнхена, прогрессивные иколь, имевшие при этом традиционную организацию учебного процесса - по типу возрожденческих мастерских. Профессиональнье традиции таких учреждений имели глубокие корни, уходящие к античным основам общеевропейской академической и художественной культуры.

Ключевые слова: Императорская Академия художеств в Санкт-Петербурге, Высшее художественное училище, художественные мастерские, икола Ажбе, икола Холлоши.
\end{abstract}

Русская академическая школа до конца XIX в. исходила из опыта европейских академий XVII-XVIII вв. C созданием в XVIII в. Академии художеств в Петербурге предшествовавшая традиция художественного образования, опиравшаяся на опыт обучения в иконописных мастерских, оказалась заменена системой академических классов. Различие терминов указывает на две разные традиции, восходящие к Средним векам. Если первая из них профессионально-цеховая, то вторая - ближе к укладу европейских университетов, имевших практику разделения учебного процесса на отдельные дисциплины и назначения на них разных преподавателей, чего не происходило в «цеховых» мастерских, которыми как правило, руководила одна личность, отвечавшая за весь процесс обучения.

Академическая реформа 1893 г. по своей направленности, казалось бы, должна была возродить прерванную автохтонную традицию обучения, но силою хода вещей она обратила отечественную художественную школу к опыту цехового обучения в европейских мастерских периода Возрождения и начала Нового времени. Применительно к художественному образованию термин «мастерская» равнозначен общекультурному понятию «академия», если понимать последнее не как учебное заведение со штатом преподавателей, а как школу отдельной личности (или же сплоченной группы мастеров с единой творческой судьбой), каковыми и являлись первые академии. Мастер лично принимал на себя ответственность за воспитание художника. И сам ученик ощущал себя не столько выпускником «казенного» учебного 
заведения, сколько восприемником традиции через мастерство конкретной творческой личности. В русских иконописных мастерских (например, в мастерской Симона Ушакова при Оружейной палате) тоже был заведен подобный уклад, но, что важно, они не являлись при этом академиями, а были лишь профессиональными объединениями, хоть и имевшими официальный статус, но обучавшими мастеров по ремесленным канонам.

Новыми мастерами, берущими на себя личную ответственность за процесс обучения, в русской Академии (Высшем художественном училище) призваны были стать передвижники. Однако практики существования академических мастерских, подобных возрожденческим и по типу организации, и по сути преподаваемого искусства (обучение которому ведется по натуре и личными умениями мастера-академика, а не по иконописным канонам или ремесленным традициям), в России не существовало. Ожидаемая и, как казалось, прогрессивная реформа ориентировалась на реализующуюся в Европе тенденцию открытия частных студий. Этот процесс, противонаправленный имевшему место ранее - уподоблению академий университетам, позволял сохранить «цеховую» суть традиций художественного образования, но через обращение уже не к средневековой традиции, а к традиции еще более глубокой - исконно академической, восходящей к античным заведениям типа Платоновской академии. Однако практическая реализация реформы в России не принесла ожидаемых результатов. Сложившаяся ситуация в Академии оценивалась современниками (В.В. Стасов, И.Э. Грабарь [1]) и исследователями [2] как упадок, еще более ощутимый, чем недостатки системы классов. Уже прижившиеся традиции академий XVIII в. были преломлены, а новая почва под ногами не ощущалась в силу отсутствия предшествовавшего опыта в русской школе.

Возникла ситуация, когда талантливая молодежь стремилась к продолжению обучения в Европе. Характерно, что наиболее притягательными оказались частные академии и студии Парижа и Мюнхена, дававшие современное (относительно эпохи модерна) образование, при этом соответствовавшее традиционным академическим требованиям. Обучение некоторых художников, будущих преподавателей (таких как Д.Н. Кардовский, В.А. Фаворский, И.Э. Грабарь), в зарубежных художественных студиях, по сути - академических мастерских (диплом одной из таких школ - частной студии А. Ажбе заверялся печатью Мюнхенской академии [3]), плодотворно сказалось на отечественной системе обучения. В дальнейшем это позволило художественной школе уже советского периода отечественной истории существовать в лице жизнеспособных учебных заведений - ВХУТЕМАС и ВХУТЕИН, органично вобравших традиции еще и московской живописной школы, несколько более самобытной.

Данная коллизия позволяет взглянуть на развитие отечественной художественной школы с позиций проблемы идентичности и заимствования традиций. Последнее словосочетание представляется парадоксальным - ведь традиция существует путем прямой преемственности. Но в данном случае обращение к опыту европейских частных студий, мастерских и академий оказалось способным восполнить разрыв традиции, возникший в русской школе искусства в конце XIX в. 
Передвижническая система мастерских из-за отсутствия соответствующего опыта в России такого исконно академического, ренессансного уклада обучения «реалистическому» искусству в плане педагогики не имела методической базы. Но все же эта система, ориентированная на персону мастера как на ключевое звено, смогла продолжить существование. Это произошло благодаря появлению в ней новых педагогов, обучившихся в зарубежных заведениях. И ключевым фактором стало даже не обретение ими личного художественного мастерства, а получение учебного опыта в мастерских, практически преемственных к эпохе Ренессанса и посредством этого - к профессиональной культуре и наследию Античности, что углубляло понимание принципов устройства академической школы.

Еще П.П. Чистякова, выдающегося художника-педагога, не устраивала сложившаяся в Академии образовательная практика, например посменные «дежурства» преподавателей в классах. Следствием этого недовольства явилось создание им неофициального объединения для дополнительного, «внеклассного» обучения, но еще при системе классов. План реформ художественного образования, казавшихся тогда прогрессивными, предусматривал и упразднение системы классов, и отстранение П. Чистякова, по обвинению в академизме [4. С. 81]. Реализация этого плана проявила отсутствие в отечественной академической школе традиции более ранней, чем система классов, - системы мастерских.

Как известно из работ Н.М. Молевой, реформа Академии художеств (Высшего художественного училища) в 1893 г., в результате которой система классов была преобразована в систему индивидуальных мастерских под руководством художников-передвижников, привела к резкому падению качества художественного образования. Опираясь на письма художников (Б.М. Кустодиева, Я.Д. Минченкова) [4], являвшихся очевидцами ситуации, автор свидетельствует: «Выпускникам Академии ставилось в вину недостаточное художественное развитие и мастерство, отсутствие твердых основ профессиональной грамотности в наиболее широком смысле этого слова, когда внешний прием исполнения и сюжета зачастую подменял наличие четкого художественного метода» [5. С. 365]. Такое положение вещей симптоматично для ситуации, когда основанное на художественном, уникальном творческом опыте, не являющееся методическим (опирающееся на основы, традиции академического образования) влияние преподавателя оказывается пагубным для учеников. Как пишет Н. Молева далее: «Сильное субъективное начало в решении вопросов художественной подготовки выражалось, в частности, в том, что даже прямые ученики Чистякова (не говоря о художниках, знавших о его методе понаслышке, от третьих лиц), беря основные положения учителя, использовали их, дополняя собственными творческими достижениями, а не пытаясь развивать общие принципы и, тем более, не обращаясь к традициям академической педагогики» [5. С. 369].

Но здесь существует некоторое противоречие: само понятие академии в изначальном значении подразумевает личностный фактор; не случайно названия академий зачастую включают имя собственное: Академия Карраччи, Академия Баччо Бандинелли, Академия Леонардо да Винчи, Платоновская академия М. Фичино. Это объясняется тем, что процесс обучения не 
происходил в таких заведениях обезличенно. Однако при этом «самобытность» («идентичность») такой системы подразумевала не только собственный, индивидуальный опыт творчества ее лидеров, но и следование локальной (европейской) традиции, которой имперсонально детерминировались относительно общие закономерности восприятия предметов, явлений и натуры.

Путь, избегающий пагубного копирования природы, натурализма (чрезмерно материалистического понимания) и при этом уходящий от «маньеризма» (и как стилистики, и как личных «манер» художников), собственно и полагался как истинный такими деятелями, как братья Карраччи. В 1582 г. в Болонье ими была основана «Accademia degli Incamminati» («Академия направленных на путь»), больше известная под названиями «Академия Карраччи», «Болонская школа Карраччи». На время открытия этого заведения во Флоренции с 1561 г. уже существовала одна их первых «официальных» академий живописи, созданная, однако, мастерами-маньеристами (Д. Вазари, А. Бронзино, Б. Амманти). Школа Карраччи, ориентировалась больше на классические ренессансные традиции, чем вызывала даже «насмешки» старых маньеристов. Однако эти «насмешки» не помешали Академии Карраччи стать центром художественного образования Италии [6]. Карраччи, по сути, представили извод ренессансных традиций для последующих поколений.

В связи с искусственностью генезиса российской Академии художеств, преемственной к традициям европейских академий XVIII в., важно подчеркнуть, что реформа, проведенная в 1893-1894 гг., на самом деле (пусть тогда еще не совсем осознанно) была возвратом к формации европейских академий, но уже образца XV-XVI вв., где ключевым элементом преподавания являлась фигура мастера. Формат большинства заведений XV-XVI вв. отличался от принципа организации академий XVIII в., с системой классов, разделявшей занятия по рисунку, живописи, композиции и анатомии по разным преподавателям. В начале XIX в., в русской Академии становятся популярными объединения вокруг крупных мастеров, например, таких, как К.П. Брюллов, но система классов при этом продолжает существование. Лишь в своей позднейшей стадии (к концу XIX в.) она официально начинает считаться неэффективной и затем упраздняется. Во время своего существования академические системы классов часто тяготели к университетским системам, казавшимся на определенном этапе развития рационализаторской мысли более «объективными», но на деле не всегда полностью применимыми к художественному образованию.

В свете этого можно сделать вывод, что основной проблемой реформы 1893-1894 гг., было не столько последовавшее за ней пагубное влияние «индивидуальностей» знаменитых художников-передвижников, сколько то, что на российской почве не было опыта функционирования заведений, подобных европейским возрожденческим мастерским, традищионно культивировавшим способы построения учебного процесса вокруг аутентичной личности. Такой формат, благодаря проходившему в определенной культурной среде интерсубъективному взаимопониманию между личностью мастера и личностью ученика, позволял осуществить наиболее полное формирование худо- 
жественной индивидуальности молодого профессионала, что и являлось целью подобного образования.

Для ученика собиравшегося поступать в мастерскую того или иного художника, традиции (как условия культурного взаимопонимания), частично представленные в индивидуальных творческих методах, и более полно в педагогических методах преподавателей, составляли предмет рефлексии и пред-понимания. Именно из-за отсутствия отчетливого представления о соответствующих академических (ренессансных и античных) традициях художественной педагогики, а не из-за «несостоятельности» русских мастеровреалистов (на тот момент уже авторитетных художников) в роли преподавателей педагогика реформированной школы и стала оказывать лишь пагубное влияние, оставляя недопонимание между учениками и учителями. Это была общая проблема структурного характера, отнюдь не сводимая к персоналиям. Во время существования возрожденческих мастерских в Европе в России преобладала совсем другая традиция изобразительного искусства и обучения ему (это, разумеется, была иконопись и ее школы). Однако к XIX в. культура передовой творческой интеллигенции в России (не меньше, а, возможно, даже больше, чем в западноевропейских странах) тяготела к первичным, чистым традициям искусства, восходящим к благородной Античности, питавшей наследием многие национальные культуры, в том числе и русскую. Но русская культура, хотя изначально и наследовавшая элементы древнегреческой, характеризуется все же отдельными от западноевропейской культуры историческими процессами, отдалявшими ее от явлений, идентичных ренессансным.

Процесс преподавания в его европеизированных основах в Высшем художественном училище при Императорской Академии художеств был восстановлен и даже углублен именно благодаря ученикам зарубежных частных студий - академических мастерских, сформированных по тем же принципам, что и мастерские эпохи Возрождения и первые академии Нового времени. Опыт возврата к традициям, полученный в аутентичной профессиональной среде $^{1}$, способствовал усвоению художниками методов и приемов, сущест-

${ }^{1}$ Мюнхен рубежа ХІХ-XX вв., по словам А. Белого, «упрочняет свою репутацию новых Афин» [8. C. 105]. Таким город хотел видеть еще баварский король Людвиг I [6], и признание известного представителя русской интеллигенции свидетельствует в пользу мнения о преобладании в Мюнхене протяженной античной культурной традиции и интересе к ней со стороны русских деятелей культуры и искусства. Подобное может быть справедливо сказано и о Париже, однако этому культурному центру были присущи более прогрессивные черты. В отличие от Парижа, в Мюнхене заметнее культивировались традиционные уклады многих сфер деятельности. Это контрастировало с образом таких городов, как, например, индустриально развивающийся Берлин [9. С. 39]. Именно традиционность Мюнхена пришлась так впору русским художникам, с которыми сами мюнхенцы видели даже ментальное родство - Россия того времени представала в глазах некоторых европейцев глубоко традиционной страной [9. С. 98], сопротивляющейся резкому прогрессу и некоторым его негативным последствиям [9. С. 42]. Индустриализация Берлина, официальной столицы, вызывала в Мюнхене негодование и нежелание следовать подобной модели развития, мюнхенские деятели культуры хотели сохранить как можно больше исконных традиций: профессиональных, художественных, культурных, даже немного отдаляясь при этом от немецких и прусских национальных традиций - отождествляя их с нежелательной берлинской моделью и противопоставляя ей свою баварскую идентичность. Все это привело к ориентации баварской столицы на старые общеевропейские традиции, которые, однако, относительно времени и окружающих условий предстали в качестве оригинальной позиции. Эту «оригинальность» и использовали русские художники в формировании своей идентичности и новой педагогики русской художественной школы. 
вовавших еще с Античности (к примеру, таких как принципы «большой линии» и «большой формы», пропагандируемые А. Ажбе и А. Гильдебрандом).

В педагогической практике таких крупных преподавателей, как Д.Н. Кардовский и В.А. Фаворский, четко просматривается линия мюнхенских частных школ (студия А. Ажбе, студия С. Холлоши [7]), но назвать это заимствованием зарубежной национальной традиции и перенесением ее на русскую почву было бы несправедливо. Многие традиции являются по своей сути синтетическими, т.е. интернациональными. Примечательная своей обособленностью и от национального, «малогерманского», искусства, и от подражаний новаторским зарубежным (французским) веяниям [9], мюнхенская школа, как и академическая петербургская, развивалась, однако, благодаря органичному синтезу и усвоению различных иных традиций, но не столько национальных, сколько профессиональных. Говоря о традициях применительно к этим школам, не следует понимать традицию как исключительно национальное явление - русское, немецкое, французское, австро-венгерское или словенское. Именно «европейскость», генетическая общность с Ренессансом и возвратом к эллинистическим основам европейской художественной культуры - вот такого рода традиционность актуальна в связи с рассматриваемым феноменом и проблемой его идентичности.

\section{Лuтература}

1. Грабарь И.Э. Моя жизнь: Автомонография. Этюды о художниках. М. : Республика, $2001.495 \mathrm{c}$.

2. Молева Н.М. Русская художественная школа второй половины XIX - начала XX века / Н.М. Молева, Э.М. Белютин. М. : Искусство, 1967. 391 с.

3. Ambrozic K. Wege zur Moderne und die Ažbe-Schule in München. Recklinghausen: Bongers, 1988. $262 \mathrm{p}$.

4. Барановский В.И. Антон Ажбе и художники России / В.И. Барановский, И.Б. Хлебникова. М. : Изд. МГУ им. М.В. Ломоносова, 2001. 256 с.

5. Молева Н.М. Выдающиеся русские художники-педагоги. М. : Изд. Академии художеств CCCP, $1962.389 \mathrm{c}$.

6. Энииклопедический словарь Ф.А. Брокгауза и И.А. Ефрона. СПб., 1898. Т. 14a-18. C. $237-593$.

7. Молева Н.М. Школа Антона Ашбе : К вопросу о путях развития художественной педагогики на рубеже XIX-XX веков / Н.М. Молева, Э.М. Белютин. М. : Искусство, 1958. 116 с.

8. Белый A. Между двух революций. Л. : Изд-во писателей в Ленинграде, 1934. 457 с.

9. Kochman A. Russian Émigré Artists in Munich, 1890-1914 : Cultural Mission and the Development of Artistic Identity : diss. ... dr of philosophy (art history) / A. Kochman ; The Univ. of Chicago. Chicago, $1997364 \mathrm{p}$.

Fomin Gleb A. Ural Federal University (Yekaterinburg, Russian Federation).

E-mail: fomin.g.a@yandex.ru

Tomsk State University Journal of Cultural Studies and Art History, 2017. № 27. 160-167 pp. DOI: $10.17223 / 22220836 / 27 / 15$

THE EUROPEAN ARTISTIC TRADITIONS AND RUSSIAN ACADEMIC SCHOOL AT THE TURN OF XIX-XX CENTURIES

Key words: Russian Imperial Academy of Arts, Higher Art School, art studios, Ažbe school, Hollósy school.

To the end of the XIX century Russian art school was subjected restructuring (as a result of the «Peredvizhniki's'» reform of the Academy in 1893-94), accompanied by clearly «entropic» phenomenon. At the same time, after the social upheavals of the beginning the XX century, the Russian Higher Art School, first as the Higher Artistic and Technical Workshops, and then as a system of art insti- 
tutes, demonstrated high vitality and powerful potential precisely as the union of individual creative workshops under the guidance of artists who gained the prestige by their own creative activity.

That system, similar to that which was conceived, but failed (as a result of the reform in 1893), relied not on the traditions of Russian Imperial Academy of Arts and Academies of XVIII century, but on the European academic traditions dating back to the XVI-XVII centuries and further, to the Renaissance academies, such as the Platonic Academy of M. Ficino. And in this beneficial change of the "paradigm", the main role was played by the Russian students of Munich private studios, who headed the national art school after the Revolution, such as: V. A. Favorsky, I. E. Grabar, and D. N. Kardovsky.

Exactly from that point of view the article discusses the problem of continuity of academic traditions in the Russian Academy at the late XIX - early XX century. This approach to the problem can be considered original, because in the works of foreign researchers, dedicated to the schools of Ažbe and Hollósy, their pedagogical and creative activity is considered mainly from the standpoint of style, the subjects of consideration appears the influences of trends in art of modernism (impressionism, post- and neoimpressionism, Cezannism, emerging expressionism). In addition, some foreign studies are entirely devoted to the political discourse about Russian émigré artists in Munich, but not the problems of the art school. The fact of such influences and connections is unquestionable, but this does not explain the piety with which the Russian artistic youth treated exactly to the pedagogical method of Ažbe - Hollósy, to the fundamental, non-stylistic and non-national foundations of that schools. The works of Russian researchers, from the classical monograph by N. Moleva and E. Belyutin, to the latest research of Baranovsky and Khlebnikova, tend to reduce the problem to P. Chistyakov's relations with professors-peredvizhniki, to misunderstanding or ignoring Chistyakov's system. Such an approach today seems insufficient, and in this connection, it seems relevant to consider the theoretical contradictions contained in previous works. In this article, the solution of such contradictions is presented trough the problem of cultural identity, encompassing two aspects: the professional aspects of creativity and art education, and the mental, the cultural features of the educational systems.

\section{References}

1. Grabar, I.E. (2001) Moya zhizn': Avtomonografiya. Etyudy o khudozhnikakh [My life: Autonomy. Etudes about artists]. Moscow: Respublika.

2. Moleva, N.M. \& Belyutin, E.M. (1967) Russkaya khudozhestvennaya shkola vtoroy poloviny $X I X$ - nachala XX veka [Russian Art School of the second half of the 19th - early 20th centuries]. Moscow: Iskusstvo.

3. Ambrozic, K. (1988) Wege zur Moderne und die Ažbe-Schule in München [Ways to Modernity and the Ažbe School in Munich]. Recklinghausen: Bongers.

4. Baranovskiy, V.I. \& Khlebnikova, I.B. (2001) Anton Azhbe i khudozhniki Rossii [Anton Azhbe and Russian artists]. Moscow: Moscow State University.

5. Moleva, N.M. (1962) Vydayushchiesya russkie khudozhniki-pedagogi [Outstanding Russian artists are teachers]. Moscow: USSR Academy of Arts.

6. Brockhaus, F.A. \& Efron, I.A. (1898) Entsiklopedicheskiy slovar' [Encyclopaedic Dictionary]. Vol. 14a-18. pp. 237-593.

7. Moleva, N.M.\& Belyutin, E.M. (1958) Shkola Antona Ashbe: K voprosu o putyakh razvitiya khudozhestvennoy pedagogiki na rubezhe XIX-XX vekov [Anton Aschbe School: On the ways of the development of art pedagogy at the turn of the 20th century]. Moscow: Iskusstvo.

8. Belyy, A. (1934) Mezhdu dvukh revolyutsiy [Between the Two Revolutions]. Leningrad: Izdvo pisateley v Leningrade.

9. Kochman, A. (1997) Russian Émigré Artists in Munich, 1890-1914: Cultural Mission and the Development of Artistic Identity. Philosophy Dr. Diss. The University of Chicago. 